\title{
Television and The Digital Revolution: A Chance for Survival
}

\author{
Nazmi T. Al-Shalabi \\ The Hashemite University, Department of English, Zarqa 13115, Jordan \\ Email : nazmi_shalabi@yahoo.com
}

\section{Doi:10.5901/mjss.2016.v7n4p}

\begin{abstract}
It is argued that today's world is marked by competition that negatively impacts the television industry which has begun losing viewers. Despite this loss of market share, television industry can survive the digital revolution by leading the way with innovation, adapting to the happenings in the niche, meeting the needs of viewers with so many options, and adopting a business model that is different, distinctive, and competitive. The discussion that employs persuasion as a method demonstrates that television is much stronger than becoming obsolete, and that the survival of television is determined not only by the change of content but also its delivery. This survival is also determined by audiences who are not for switching over to online video streaming services, and who prefer television to other outlets because of its programs, especially sports and shows. It has been demonstrated that television has its own place, that it is capable of competing with online services, and that it will be triumphant.
\end{abstract}

Keywords: competition, inundated, penetration, evaluation, entice, options, adapt itself

\section{Introduction}

Scholars claim that television is a medium that physically connects two or more people into a confined space (Morrison and Krugman, 2001). They also refer to television as a "cultural forum" where people discuss numerous topics (Newcomb, 1994), or an "electronic hearth" which brings people together (Tichi, 1991). These scholars are talking sense because television connects people who sit together to watch a certain program. People themselves take part in programs, such as shows and talk about various issues. Acting upon their own experiences, these people make remarks and comment on a certain argument. When these people do so, they reflect their own views and understandings of a certain problem, and, in this case, it's up to audiences to accept or reject these views that often generate heated debates in which some viewers argue for a certain opinion and others argue against it. Just as the views in this program generate debates so do other programs. In these debates members of the same family sometimes differ over a certain view. This difference itself may give rise to quarrels because there are viewers who reject persuasion. Thus, they insist on their own views and refuse to change their minds, which provides the indication that they are not only too pig-headed to understand and act accordingly but also strange humans.

Equally strange is also television viewing itself. Some academics have described television viewing as a "fundamentally isolating experience - one that gives the illusion of contact with the world while discouraging actual human contact "(Hoynes, 1994) - as well as an experience that fosters disengagement from reality and threatens formation of self-identity due to the lack of social interaction"(Davis, 2000). The strangeness of this experience lies in the viewer's taking himself/herself to be in touch with others, but in reality he/she is isolated in a confined space and disengaged from reality. This viewer feasts his/her eyes on an imagined world that does not necessarily reflect reality as it has been fabricated by the director who has a number of tools at his disposal. While watching television, this disengaged-from-reality viewer remains glued to the set, and becomes so immersed in viewing that he/she grows to be unaware of all that occurs in his/her niche. This situation clarifies the profound influence of television on the viewer's mind.

Since the 1950s, television has been having a great impact not only on viewers' minds but also their psyches, eyes, bodies and daily routines(Marling, 1996). Lacking social interaction, viewers feel that they are self-divided and unable to assert their self-identities. These viewers also suffer because watching television for a long time hurts their eyes, which leads to a visual impairment. The nearer these viewers to the television set are, the weaker their eyesight becomes. The best thing to be done in this case is to stop viewers from sitting near to the TV set, and to send them without further delay to the doctor for an eye test because the failure to detect visual impairment early " may have a permanent effect on long-term vision outcomes, education achievement and self-esteem"(Bener, 2012). Bener is right 
because the early detection of visual impairment makes it easy for the doctor to prescribe an appropriate medicine that leads to recovery. On the contrary, the late detection of this problem lessens the chance for recovery on the grounds that visual impairment becomes chronic. This state impacts the victim's achievement and sense of pride. Taking this problem into account, parents should keep an eye on their children and not let them watch television programs on their own because the content of certain programs is not good. To take an example, a program replete with acts of violence does children harm and so does the program that involves crimes. It is worth noting that content represents the panacea for the television industry which is now pressurized to maintain its status in the face of a great competition that is certain to negatively impact it. This competition is currently gaining momentum due to the internet penetration, viewers' being inundated with technology and becoming tech-savvy, and the mounting numbers of people who watch television shows " online and on demand"(2). These numbers mean that online streaming services are becoming popular because they give people the opportunity to access online content freely and at a low cost. This state constitutes a good reason for television industry to carefully re-examine the manner in which it operates. Such a careful examination is a prerequisite for figuring out the course of action to be taken. As far as action is concerned, the course of action that the people in charge of television industry can take should focus on customers' needs. One of these needs is entertainment. When television provides this entertainment at an affordable rate, it wins customers over and stops them from straying away. In this way, the popularity of television increases and the sales of online streaming services plummet. Another need is education. Viewers hold the television set to be an educational tool. Those in charge of television industry should rise to viewers' expectations and provide programs that educate them. They can show programs that instruct viewers on how to evade, for instance, social evils, such as the obsession with appearances that leads to hypocrisy, creates numerous troubles for them, and forces them to resort to lying. Another social evil is jealousy .Viewers can learn about it by watching films, such as William Shakespeare's Othello, in which the central character, Othello, is maddened by jealousy, which is conducive to killing his loving wife, Desdemona. A third social evil is bribery. To show viewers how evil bribery is those in charge of television industry can pick programs that deal with it. When the television set does these two jobs, entertainment and education, viewers feel satisfied, which increases its popularity.

This popularity itself empowers television industry and infuses a new life into it, which makes television much stronger than becoming obsolete. This television strength can be reinforced by re-examining the content of programs. An examination of this sort should lead to creating a great content that meets customers' demands. To achieve this objective, this content should entice viewers into enjoying the programs, keep them glued to their television sets, and address their concerns be they poor or rich. This content should also be multifarious. In a sense, television shouldn't keep showing the same programs. If it does, viewers get bored and start looking for other ways of entertainment. Furthermore, the change of content is a prerequisite for not only being competitive but also victorious in a niche "of people who have millions of other options"(Todd, 2013). Todd adds that "perhaps the best way to be new and different these days is to try dipping into the past" (1).

\section{Literature Review}

Most people in this review of literature talk sense and argue for the survival of television. To take an example, Bill Thompson (2004) maintains, in "Why TV Will Survive the Internet, " that television " is going to survive in the networked world, just as books, film, and even radio survived in the television-dominated 1970s and 1980s." Like Thompson, Marsha Friedman (2010) argues, in "Traditional Media Not Going Away: Why Radio, TV and Print Will Survive the Rise of the Internet, " that it is not expected that " traditional media - newspapers, radio and TV" will " disappear anytime soon." She adds that those who " predict the death of traditional media could not be more wrong."

As regards survival, a few writers address television industry suggesting that certain strategies be followed to guarantee the survival of TV. One of these writers is Jeff Kagan (2014)who claims that people in this industry can "lead the way with innovation." Kagan adds that these people must " cannibalize themselves and reinvent themselves for the future." Another one is Greg Satell (2015) who claims that television companies "will have to innovate their business model to survive." A third one is Natalia (2015) who maintains that television " needs to adapt ... in order to survive the digital revolution" (1). She adds that "television stations will have to embrace the internet and utilize the many possibilities offered by it "(1). Natalia seems to be talking sense because adaptation helps television with maintaining its status, competing with other sources of entertainment, and fitting in a world marked by cruelty, deception, immorality, and theft. Commenting on the television business in such a world, Hunter S. Thompson holds that the television business is "a cruel and shallow money trench, a long plastic hallway where thieves and pimps run free, and good men die like dogs "(quoted by Peter Marshall, 2012). This business done by "thieves and pimps " who run free in a niche where " good men die like dogs "(1) is not expected to do viewers good or do television itself any good. This business should be modified to 
empower television and contribute to its being existent in the world of digital revolution.

The preceding arguments and works reveal the consensus on the survival of TV. As long as these arguments are acceptable and relevant, I have used all of them in this study devoted to demonstrating that TV is a survivor.

\section{Significance of the Study}

This study is beneficial to the whole society, individuals, television industry, and researchers. It meets the needs of people who cannot live without television, who insist on using TV, who are too poor to have access to the internet, and who object to switching to the online streaming video. It is also beneficial to the individuals who have been used to keeping television sets at home and to watching programs with their neighbors and/or friends. These individuals realize that television has become an important part of their lives and that it keeps them connected with others. Furthermore, this study is equally beneficial to people in the TV industry. It makes it clear that television can survive by leading the way with innovation, reconsidering its content along with its delivery, and adapting itself to the happenings in the digital world. The value of this adaptation is that it empowers TV and enables it to compete with other sources of entertainment. In addition to all that has been said, this present study does researchers good because it serves as a future reference for them on the subject of television and digital revolution that is the focus of this study that relies on persuasion to convince the reader of my own point of view that TV will survive the digital revolution.

\section{Methodology}

I have chosen to write a persuasive essay that concentrates on persuading the reader of my opinion that TV has a chance for surviving the digital revolution. I give this reader good reasons for my argument and keep doing my utmost to convince him/her of my viewpoint and win him/her over.

\section{Discussion}

This survival of TV necessitates that people in charge of television industry take the initiative and be innovative. Speaking of innovation, Megan O'Neill (2011) argues that television networks "should start producing web only content in order to cement their spot in a world of web video" O'Neill adds that networks "concerned with the decline of viewership can offer viewers incentives for watching live" (2011). O'Neill is right for incentives indicate that television networks care for viewers and prioritize their desires, which makes them feel satisfied, and, consequently, go on with watching television programs. These viewers themselves can be also venerated by being allowed, Looney claims, "to produce some of our content themselves "(1). This job can be done via a contest "to see," Looney adds, "who has the best video, or simply challenging the viewers to find a news story" (1), which gives them a " chance for recognition "(1). In so doing television industry creates great and interesting content which is in great demand these days.

This demand for great content is expected to keep getting higher and higher for a number of reasons .Firstly, viewers have limitless options and alternatives. Despite that, they turn to the television as it offers certain live programs, such as sports and quality shows. It is true that viewers can watch television-quality shows through Netflix which is a video-streaming firm, but they have to turn to television to watch the sports programs. Secondly, viewers turn to television to watch the news channels. Thirdly, some viewers are not for switching over to streaming services which are still unfamiliar. Fourthly, there are viewers who also reject streaming services because they can keep up with the show they want, and can't wait until it comes out on, for instance, Netflix that doesn't have recent shows and new sports games. Fifthly, some audiences are still tenacious of television programs. Arguing in support of this contention, Natalia quotes The Wall Street Journal's argument that " an estimated 5\% of television audiences in the United States remain unprepared for the digital conversion resulting in the loss of signal and decreasing ratings for local affiliates"(1).

Sixthly, some people cannot live without television. Chris Richards(2015) refers to researchers who have surveyed nearly 2000 British adults that have been asked to name the things in life they can't live without. The majority of the men surveyed have chosen television as the most important thing in life. Seventhly, some people are not in a position to switch over to the internet because they are too poor to do so. The inevitable result is that they stick to their television sets and gather in their living rooms to watch programs. Reckoning with the preceding reasons, it becomes quite clear why television industry should focus on content that is at the center of audiences' attention, that bears upon the popularity of television, that enables television to compete with online streaming video services, and that is conducive to the survival of television and expanding its presence in a world of limitless choices. This focus on content seems to be the recipe not only for survival but also for distinction. 


\section{Conclusion}

The preceding arguments demonstrate that television is capable of competing with online video-streaming companies, that it will be victorious in a world where almost everyone can not just create interesting content but also distribute it to audiences living far away, and that it will survive the digital revolution.

\section{References}

Abdulbari, Bener and Huda S. Al-Mahdi.(2012). Internet use and television viewing in children and its association with vision loss: A Major Public Health Problem. Journal of Public Health in Africa. 3(e16) : 65-69.

Berrios, Natalia.(2015).Can local television survive the digital revolution?." Dead. Reckoning. Net Facultynh.syr.edu/masiclat/DeadReckoning/BerriosLocalTV.html Accessed Dec.15th, 2015.

Davis, J. (2000). Identity and social change .New Brunswick, N. J. : Transaction.

Friedman, Marsha(2010). Traditional media not going away :Why radio, tv \& print will survive the rise of the internet. emsincorporated.com/traditional-media-not-going-away-why-radio-tv-and-print-will-survive-the-rise-of-the-internet/

Hoynes, W. (1994).Public television for sale: Media, the market, and the public sphere. Boulder, Colo.: Westview.

Kagan, Jeff.(2014). Can cable tv survive?" www.equities.com/editors-desk/stocks/telecommunication/can-cable-tv-survive

Looney, C. (2012). Where is the future of television taking us ? Media Transformation.

Marling, K. (1996). As seen on tv: The Visual culture of everyday life in the 1950s. .Cambridge, Mass.: Harvard University Press.

Marshall, P.D.(2012). How to work and survive in the film and tv industry: The 10 Commandments of filmmaking. Filmmaking Tips for the Independent Filmmaker. Actioncutprint.com/filmmaking-articles/10-commandments/

Morrison and D.Krugman.(2001). A look at mass and computer mediated technologies: Understanding the roles of television and computers in the home. Journal of Broadcasting and Electronic Media 45(1):135-161.

Newcomb, H. (1994).Television : The Critical View .5th Edition. New York : Oxford University Press.

O'Neill, Megan.(2011). 5 Ways the tv industry can survive the online video boom. www.adweek.com/socialtimes/5-ways-the-tv-industrycan-survive-the-online-video- boom/37041

Richards, Chris.(2015).www.mirror.co.uk/news/uk-news/british-men-cannot-live-without-6236738

Satell, Greg.(2015). The future of tv is here. Can cable survive? www.forbes.com/sites/gregsatell/2015/06/06/the-future-of-tv-is-here-cancable-survive

Shakespeare, William. (2001). Othello. Kindle Edition. Signet Classics.

Tichi, C. (1991). Electronic Hearth: Creating an American Television Culture . New York : Oxford U.P.

Thompson, Bill.(2004). Why tv will survive the internet News.bbc.co.uk/2/hi/technology/4071573.stm

VanDerwoff, Todd.(2013). Let's save network television." www.avclub.com/article/lets-save-network-television-96499 